\title{
BFFECTS OF PRIMARY RECOIL ENERGY ON THE PRODUCTION RATE OF MOBILE DEFECTS DURING ELEVATED TEMPERATURE IRRADIATION*
}

\author{
P. R, Okemoto, L, E. Rehn and R. S, Averback \\ Materialo Science and Technology Diviston \\ Argonne National Laboratory \\ Argonne, Illinois 60439
}

CONF-841246--19

DE85 006218

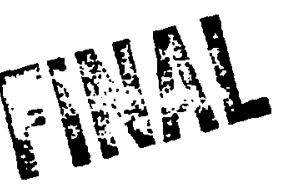

November 1984

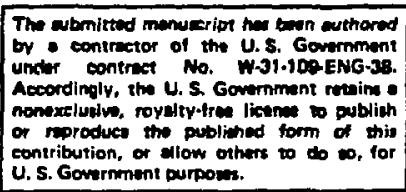

\section{DISCLAIMER}

This report was prepared as an account of work sponsored by an agency of the United States Government. Neither the United States Government nor any agency thereof, nor any of their employees, makes any warranty, express or implied, or assumes any legal liability or responsibility for the accuracy, completeness, or usefulness of any information, apparatus, product, or process disclosed, or represents that its use would not infringe privately owned rights. Reference herein to any specific commercial product, process, or service by trade name, trademark, manufacturer, or otherwise does not necessarily constitute or imply its endorsement, recommendation, or favoring by the United States Government or any agency thereof. The views and opinions of authors expressed herein do not necessarily state or rellect those of the United States Government or any agency thereof.

Submitted to the First International Conference on Fusion Reactor Materials, December 3-6, 1984, Tokyo, Japan.

*Work supported by the U. S. Department of Energy. 
EFFECTS OF PRIMARY RECOIL ENERGY ON THE PRODUCTION RATE OF MOBILE DEFECTS DURING ELEVATED TEMFERATURE IRRADIATION*

P. R. Okamoto, L. E. Rehn and R. S. Averback Materials Science and Technology Division Argonne National Laboratory Argonne, I1lino1s 60439

\section{ABSTRACT}

Radiation-induced segregation rates in a Ni-12.7 at. $\mathrm{X}$ Si alloy have been measured as a function of temperature using lons of various masses and energies. An analysis of the segregation kinetics using a simple analytical model yielded the relative efficiency of each of the lons for producing mobile defects directly from ratios of their measured segregation rates. In this paper, we also show that the reilative efficiencies can also be determined from measured shifts in the peak segregation temperature. Both methods yield a strong decrease in efficlency wh increasing ion mass. The reduction in efficiency for the heavior lons was found to be significantly larger than that measured at very low temperatures by resistivity techniques. The latter are often used as a basis for correlating damage structures produced at elevated temperatures. Differences between the low and high temperature measurements indicate that relative efficiencies determined from segregation measurements are more reliable for correlating microstructural changes that are produced in different irradiation environments at high temperatures. 
EFEECTS OF PRIMARY RECOIL ENERGY ON THE PRODUCTION RATE OF MOBILE

DEFECTS DURING ELEVATED TEMPERATURE IRRADIATION*

\section{P. R. Okamoto, L. E. Rehn and R. S. Averback Materials Sclence and Technology Division Argonne National Laboratory Argonne, Illino1s 60439}

\section{Introduction}

Despite its greater technological importance, less is known about defect production mechanisms at elevated temperatures then is known at very low temperatures. For predicting microstructural changes at elevated temperatures, the quantity of interest is the rate of production of mobile defects. Due to defect interactions within cascades, the net production rate of mobile defects can be only a small fraction of the calculated atomic displacement rate (dpa/s) which is commonly used to correlate damage structures produced by different irradiation particles. Hence the production efficiency for mobile defects must be known as a function of the irradiation species and energy before quantitative correlations between different Irradiation environments can be made.

Recent.ly, Okamoto et al., [1] proposed a method for determining the relative efficiencles of different particles directly from ratios of measured segregation rates of $\mathrm{SI}$ in irradiated N1-S1 alloys. Here it is shown that the relative efficiencies can also be obtalned from messured shifts in the peak segregation temperature. Efficlencles obtained by these methods from measurements of radiation-1nduced segregation in a Ni-12.7 at.Z S1 alloy are In good agreement with those obtained by computer fitting techniques. A detalled account of the experimental measurements and analysis can be found in Ref. 2. 
2. Method of Analysis

When N1-Si alloy are Irradiated at elevated temperatures, preferential transport of Si $\mathrm{by}$ defect fluxes toward the surface results in the formation and growth of $\mathrm{Hi}_{3} \mathrm{SI}$ surface coztings [3]. Previous work [4-6] has shown that the coatings obey parabolic growth kinetics, i.e., the coating thickness, W, as a function of irradiation time $t$ is given by

$$
W(t)=A t^{1 / 2}
$$

where $A$ is the growth-rate constant expressed in units of length/(time $)^{1 / 2}$. The growth constant provides a simple quantitative measure of the segregation rate Induced by the Irradiation. As shown by okamoto et al., [1], the temperature and dose-rate dependences of the growth constant can be exploited to obtain information about the production efficiencies of lons for producing mobile defects. Detalls of the coating growth model and the original analysis for extracting such information is given in Ref. 1 . Here we focus on the additional information contained in the dose-rate dependence of the peak segregation temperature.

The model assumes that coating growth is controlled by the diffusion of tightly bound Si-interstitial $(8-1)$ complexes toward the surface. Except in a S1 depleted zone Immediately beneath the surface coating, quasi-steady-state conditions for vacancies and s-1 complexes are assumed during coating growth. According to the model, the growth-rate constant expressed in units of length/(dose) $)^{1 / 2}$, is given by

$$
A_{K} \equiv \frac{A}{K_{c}^{1 / 2}}=\left[\frac{2 C_{8}^{0}}{C_{8}^{P}\left(C_{8}^{P}-c_{8}^{0}\right)}\right]^{1 / 2} \cdot\left(\frac{D_{18} C_{1 B}}{K_{c}}\right)^{1 / 2}
$$


where $K_{C}$ is the calculated atomic diaplacenent rate, $C_{B}^{0}$ is the bulk S1 concentration, $C_{g}^{P}$ is the concentration of $S 1$ in the surface coating, $D_{18}=$ $(2 / 21) a_{0}^{2} v_{18} 18$ the diffusion coeffictent of the $8-1$ complexes, $a_{0}$ is the latt1ce parameter, $v_{1 s} 18$ the jump frequency of the $8-1$ complexes, and $C_{1 s} 1 s$ their ateady-state bulk concentration 1mmediately behind the S1 depleted zone. By use of conventional rate theory [7], 1t has been shown [1] that

$$
\frac{D_{1 s} C_{18}}{K_{c}}=\frac{2}{21} a_{0}^{2}\left(\frac{E}{P_{1}}\right) s(n, B)
$$

where $\varepsilon=\mathrm{K}_{0} / \mathrm{K}_{\mathrm{c}}$ is tihe production efficiency for mobile defects, $\mathrm{K}_{\mathrm{o}}$ is the actual production rate of mobile defects, and $P_{1}$ is the total sink annihilation probability for Interstitials. $S(n, \beta)$ is the fraction of defects annihilating at sinks and is given by [1]

$$
s(\eta, \beta)=\frac{2}{n}(1+\beta)\left\{\left[1+\frac{n}{(1+\beta)^{2}}\right]^{1 / 2}-1\right\}
$$

where

$$
n=\frac{4 a_{r}\left(v_{v}+\frac{1}{7} v_{18}\right)}{v_{v} v_{1 s}{ }^{P} p^{P_{1}}}, B=\frac{a_{r}\left(v_{v}+\frac{1}{7} v_{18}\right)}{v_{18} P_{1}} \bar{c}_{v}
$$

In Eq. (5), a $a_{r}$ is the number of lattice sites in the recombination volume for vacancies and -1 complexes, $\nu_{v}=v_{v}^{0} \exp \left(-H_{v}^{m} / k T\right)$ is the vacancy fump frequency, $\nu_{v}^{0}$ is the jump attempt frequency, $H_{v}^{m}$ is the vacancy migration energy, $\bar{C}_{v}=\exp \left(S_{v}^{E} / k\right) \exp \left(-H_{v}^{F} / k T\right)$ is the average thermal-equilibrium concentration of vacancies, $S_{v}^{F}$ is the vacancy entropy of formation, $H_{v}^{F}$ is the vacancy formation energy, and $P_{v} 18$ the total sink annihilation probability for vacancies. 
Internal friction studies [8] Indicate that s-1 complexes are considerably more woblle than vacancles $\left(D_{16} \gg D_{v}\right)$. For this condition, it has been shown [1] that at low temperatures where defects are annihilated mainly by recombination,

$$
A_{K}=\frac{2}{3}\left[\frac{2 c_{8}^{0}}{C_{8}^{P}\left(C_{8}^{P}-c_{8}^{0}\right)}\right]^{1 / 2}\left[\frac{a_{0}^{2} \varepsilon D_{v}}{a_{r} K_{c}}\right]^{1 / 4}
$$

and at high temperatures where $n<(1+B)^{2}$,

$$
A_{K}=\frac{2}{3}\left[\frac{2 c_{8}^{\circ}}{c_{8}^{P}\left(c_{8}^{0}-c_{8}^{0}\right)}\right]^{1 / 2}\left[\frac{a_{0}^{2} e}{a_{r} \bar{c}_{v}}\right]^{1 / 2}
$$

These solutions are sketched in Fig. 1 for the case $\varepsilon=1$. They show that the apparent activation enthalpy of the growth-rate constant is equal to $\mathrm{H}_{\mathrm{v}}^{\mathrm{m}} / 4$ at low temperatures, and to $\mathrm{H}_{\mathrm{v}}^{\mathrm{F}} / 2$ at high temperatures. Equation (6) also shows that the growth-rate constant varies inversely with the $1 / 4$ power of the calculated dose-rate at low temperatures, and is independent of dose-rate at high temperatures.

The temperatures dependence of the growth-rate constant is contained primarily in the sink annihilation fraction, $s(n, B)$. Hence the temperature $T_{m}$ at wich the growth-rate constant is a naximum w11 be given approximately by the temperature at which $\mathrm{dS} / \mathrm{d}(1 / \mathrm{kT})=0$. To obtain an approximate analytical solution, the quantity $\left[1+n /(1+\beta)^{2}\right]^{1 / 2}$ In Eq. (4) can be expanded. Only the first four terms in the expansion are needed to define the peak. The solution for the case where $n \ll\left(1+\beta^{2}\right)$ and $\beta^{2} \gg 1$, 1.e., when recombination is dominant over defect annihilation at sinks, is given approximately by 


$$
T_{m}=\frac{H_{v}^{m}+2 H_{v}^{F}}{k \ln \left[\frac{3 a_{I} v_{v}^{O} \exp \left(2 S_{v}^{F} / k\right)}{2 \varepsilon K_{c}}\left(\frac{H_{v}^{F}+M}{H_{v}^{m}-2 M}\right)\right]}
$$

where

$$
M=\frac{1}{P_{1}} \frac{d P_{1}}{d(1 / k T)}
$$

Equation (8) shows that for bombarding particles with identical efficiencies, the peak segregation temperature will increase with increasing calculated dose-rates. It also shows that for irradiations carried out at the same calculated dose-rates but with particles of different efficlencies, the more efficient particle will have the higher peak segregation temperature.

The factor $M$ depends on the temperature dependence of the sink annihilation probability. Our own electron microscopy observations indicate that near the peak segregation temperature, the sink density is relatively low In the region of interest, namely less then a few tenths of a micron below the bombarded surface. However, at these relatively shallow depths the surface acts as a strong sink for defects. Hence for the present calculations, the surface will be assumed to be the dominant sink. As shown by Lam et. al., [9] the surfaces of a foil of thickness $L$ are equivalent to a sink annihilation probability given by

$$
P_{1}=\frac{2}{21} a_{0}^{2}\left(\frac{12}{L^{2}}+\frac{3}{L} f_{0}^{1 / 4}\right)
$$


where

$$
f_{0}^{1 / 4}=\left(\frac{3 a_{r} o k_{c}}{a_{0}^{2} y_{v}}\right)^{1 / 4}
$$

When the second term in Eq. (10) becomes the dominant term, 1.e., for very thick foils, the defect concentration profiles approaches that for a semiinfinite medium. In this case, it can be seen from Eq. (9) and (11) that $M$ becomes a constant equal to $\mathrm{H}_{\mathrm{v}}^{\mathrm{m}} / 4$, resulting in a decrease in $T_{m}$ relative to the case where $P_{1}$ is independent of temperature.

Before applying Eqs. (6), (7) and (8) to experimental data, it is important to note that the recombination volume parameter $a_{r}$ and the production efficlency factor, $\varepsilon$, always enter these equations as a ratio. Hence a unique value for the efficlency cannot be obtained by fitting experimental data unless $a_{r}$ is known. However, Eqs. (6), (7) and (8) can be used to determine the ratios or the relative efflciencles of two different particles ( 1 and 2 ) using only the known or measurable quantities, $A_{k}, K_{c}, H_{v}^{m}$, $H_{v}^{F}, T_{m}$, and $T$. From Eq. (6), the relative efficiencies in the low temperature recombination dominant region are given by

$$
\frac{\varepsilon_{1}}{\varepsilon_{2}}=\frac{K_{c}^{(1)}}{K_{c}^{(2)}}\left[\frac{A_{K}^{(1)}}{A_{K}^{(2)}}\right]^{4} \exp \left[-\frac{H_{v}^{m}}{K}\left(\frac{1}{T(2)}-\frac{1}{T}\right)\right]
$$

and from Eq. (7), in the higher temperature regime,

$$
\frac{\varepsilon_{1}}{\varepsilon_{2}}=\left[\frac{A_{K}^{(1)}}{A_{K}^{(2)}}\right]^{2} \exp -\left[\frac{H_{V}^{F}}{2}\left(\frac{1}{T}(1)-\frac{1}{T^{(2)}}\right)\right]
$$


In the intermediate temperature recombination dominant regime, Eq. (8) gives

$$
\frac{\varepsilon_{1}}{\varepsilon_{2}}=\frac{\mathrm{k}_{\mathrm{c}}^{(2)}}{\mathrm{k}_{\mathrm{c}}^{(1)}} \exp \left[-\frac{\left(\mathrm{H}_{\mathrm{v}}^{\mathrm{m}}+2 \mathrm{H}_{\mathrm{v}}^{\mathrm{F}}\right)}{\mathrm{k}} \frac{1}{\left(\frac{1}{\mathrm{~T}_{\mathrm{m}}^{(1)}}-\frac{1}{\mathrm{~T}_{\mathrm{m}}^{(2)}}\right)}\right]
$$

It 18 important to emphasize that the above equations are applicable only under Irradiation conditions where mutual recombination is the dominant mode for defect annihilation.

\section{Compar1son w1th Exper1ment}

In this section, the equations obtained in the previous section are applied to recent coating growth measurements obtained from a N1-12.7 at.\% Si alloy. Detalls of the experimental procedures and measurements are given in Ref. 2.

In F1g. (2), taken from Ref. 2, coating growth measurements carrled out over the temperature range from 350 to $650^{\circ} \mathrm{C}$ are shown for $81 x$ different 1rradiations. The results reveal that for particles of approximately the same energy, a large reduction in the growth-rate constant occurs with increasing Ion mass. The He data exhibit the predicted [cf. Eq. (6)] 1nverse 1/4 power dependence of the growth-rate constant on dose-rate at lower temperatures, and no dependence on dose-rate at higher temperatures. A least squares fit yields apparent activation energies of $0.31 \mathrm{eV}$ and $0.75 \mathrm{eV}$ for the low and high temperature Arrhentus reglons, respectively. It follows from Egs. (6) and (7) that $\mathrm{H}_{\mathrm{v}}^{\mathrm{m}}=1.24 \mathrm{eV}$ and $\mathrm{H}_{\mathrm{V}}^{\mathrm{F}}=1.5 \mathrm{eV}$. The He data also exhibit the shift Icf. Eq. (8)] In the peak segregation temperature to higher temperatures with Increasing dose-rate, expected of particles of Identical production efficiencies. A comparison of the proton and the lower dose-rate He data also -how the expected shift to higher temperatures in the peak segregation 
temperature of the more efficient particle, when irradiations using two different particles are carried out at the same calculated dose-rate.

Using Eq. (2), a computer fitting procedure was used to obtaln "best fit" IInes [cf. Fig. (2)] using the ratio $\left(\varepsilon / a_{r}\right)$ as the main fitting parameter. The Bink annihilation probability given by Eq. (10) was employed in the calculations using $l=800 \mathrm{~nm}$. The other parameters used in the calculations are: $\quad H_{v}^{m}=1.24 \mathrm{eV}, \mathrm{H}_{\mathrm{v}}^{F}=1.5 \mathrm{eV}, \mathrm{s}_{\mathrm{v}}^{\mathrm{m}}=5 \mathrm{~K}, \mathrm{v}_{\mathrm{v}}^{\mathrm{O}}=5 \times 10^{13}, \mathrm{H}_{1 \mathrm{~s}}^{\mathrm{m}}=0.6 \mathrm{eV}$, and $a_{0}=3.52 \times 10^{-8} \mathrm{~cm}$. The ratios $\left(\varepsilon / a_{r}\right)$, relative efficiencies (relative to the 1-MeV H), and the peak segregation temperatures obtained from the best fit cases are listed in Table 1. The relative efficiencles and peak segregation temperature obtalned from Eq. (14) and (8) are also listed.

As shown in Table 1, the peak segregation temperatures obtained from Eq. (8), and the relative efficiencies of different particles determined fron the relative shift in their peak segregation temperatures are in good agreement with those obtained from the proton through $\mathrm{N} 1$ data using computer fitting techniques. This implies that mutual recombination was the dominant defect annihilation mode for these irradiations. On the other hand, the Kr data could not be fitted consistently either with Eq. (14) or with Eq. (2). This Indicates that Irradiation Induced sinks comparable to or greater than the equivalent sink density of the surface were produced during the $\mathrm{Kr}$ 1rradiation, particularly at the lower temperatures. Therefore, the efficiency for Kr Ilsted in Table 1 represents only a minimum value obtained by fitting data obtalned at temperatures above $550 \mathrm{C}$.

The relative efficlencles normalized to the 1-HeV protons obtained for the best fit cases, are plotted in Fig. 3 as a function of the reighted-average recoll energy, $P_{1 / 2} \cdot P_{1 / 2}$ is that primary recoll energy above and below which half the defects are produced. It lo a measure of the spatial 
distribution of the defect production. A detalled discussion of $P_{1 / 2}$ can be found in ref. 10. Figure 3, taken from Ref. 2, provides a quantitative representation of the relative efficiency for producing mobile defects as a function of the "hardness" of the primary recoll spectrum. The general shepe of the curve is qualitatively similar to the curves of efficiency versus $P_{1 / 2}$ obtained by Averback et al. [10] who used electrical resistivity measurements to study defect production at very low temperatures in copper and silver over a wide range of recoll energies. Howicver, there are significant quantitative differences. The resistivity mexsurements saturate at an efficlency which was st111 about $40 \%$ of that found at the lowest primary recoll energy. In contrast, the limiting value in Fig. 3 appears to be considerably less, i.e., only about $10 \%$ or less than that found at the lowest priwary recoll energy.

It is Important to recognize that the electrical resistivity changes measure the total number of stable defects which are introduced during Irradiation, whereas the coating-growth measurements are sensitive only to those mobile defects wh1ch particlpate in long range atom transport, i.e., only some fraction of the total monitored by resistivity changes. The quantitative difference is also of technological significance. Defect production efficlencles obtalned at very low temperatures are often used as a basis for correlating mfcrostructural changes induced by different bombarding particles at elevated temperatures. However, the fact that quantitative differences exist suggests that the relative efficlencles determined from coating-growth measurements offer a more rellable basis for correlating radiation effects induced at elevated temperatures. 
Table 1. Relative Efficlencies and Peak Segregation Temperatures

\begin{tabular}{|c|c|c|c|c|c|c|c|}
\hline particle & & $\underset{\left(\operatorname{dps} f_{B}\right)}{\mathbf{K}_{G^{\prime}}}$ & $\left(\varepsilon / a_{r}\right)$ & $\begin{array}{l}T(K) \\
\text { (num) }\end{array}$ & $\begin{array}{c}T(K) \\
(\mathrm{Eq} \cdot 8)\end{array}$ & $\begin{array}{c}\varepsilon / \varepsilon_{p} \\
\text { (num) }\end{array}$ & $\begin{array}{c}\varepsilon / \varepsilon_{\mathrm{P}} \\
\left(\mathrm{Eq} \cdot \mathrm{P}_{4}\right)\end{array}$ \\
\hline $1.0 \mathrm{MeV}$ & $\mathbf{H}$ & $2.6 \times 10^{-5}$ & $1.51 \times 10^{-3}$ & 818 & 818 & 1.00 & 1.00 \\
\hline $2.0 \mathrm{MeV}$ & He & $2.6 \times 10^{-5}$ & $7.14 \times 10^{-4}$ & 808 & 810 & 0.47 & 0.48 \\
\hline $2.0 \mathrm{MeV}$ & $\mathrm{He}$ & $3.1 \times 10^{-4}$ & $7.14 \times 10^{-4}$ & 843 & 843 & 0.50 & 0.50 \\
\hline $2.0 \mathrm{MeV}$ & 21 & $3.1 \times 10^{-4}$ & $5.56 \times 10^{-4}$ & - & - & 0.37 & - \\
\hline $3.0 \mathrm{MeV}$ & $\mathbf{N 1}$ & $6.9 \times 10^{-4}$ & $1.19 \times 10^{-4}$ & 828 & 828 & 0.08 & 0.08 \\
\hline $3.25 \mathrm{MeV}$ & $\mathrm{Kr}$ & $3.1 \times 10^{-4}$ & $1.59 \times 10^{-5}$ & - & - & 0.01 & - \\
\hline
\end{tabular}




\section{References}

[1] P. R. Okamoto, L. E. Rehn and R. S. Averback, J. Nucl. Mater. 108-109 (1982) 319.

[2] L. E. Rehn, P. R. Okamoto and R. S. Averback, Phys. Rev. B 30 (1984) 3073.

[3] D. I. Potter, L. E. Rehn, P. R. Okamoto and H. Wiedersich, St. Metall. 11 (1977) 1095.

[4] L. E. Rehn, R. S. Averback and P. R. Okamoto, Advanced Techniques For Characterizing Microstructures, eds. F. W. Wiffen and J. A. Spitznagel (AIME, Warrendale, PA, 1982) p. 269.

[5] R. S. Averback, L. E. Rehn, W. Wagner, H. Wiedersich and P. R. Okamoto, Phys. Rev. B 28 (1983) 3100.

[6] T. Moroga, P. R. Okamoto and H. Wiedersich, Radia. Eff. Lett. 68 (1983) 163.

[7] H. Wiedersich, Radia. Eff. $\underline{112}$ (1982) 111 .

[8] P. R. Okamoto, L. E. Rehn, R. S. Averback, K. Y. Robrock and H. Wiedersich, in: Point Defects and Defect Interactions in Metals, eds. J. Takamura et al. (University of Tokyo Press, Japan, 1982) p. 946.

[9] N. Q. Lam, S. J. Rothman and R. Sizemann, Radia. Eff. 2353.

[10] R. S. Averback, R. Benedek and K. L. Merkle, Phys. Rev. B 18 (1978) 4156. 
12

Figure Captions

FIg. 1. Schematic Arrhenius plot of the predicted temperature dependence for coating growth.

Fig. 2. Arrhenius plot of the measured parabolic growth-rate constants for $\mathrm{Ni}_{3} \mathrm{~S} 1$ coatings on $\mathrm{N} 1-12.7$ at. $\mathrm{S}$ S alloys for different Ion Irradiation.

Fig. 3. Relative efficiencies of various tons for producing mobile defects plotted as a function of the weighted-average recoil energy. 


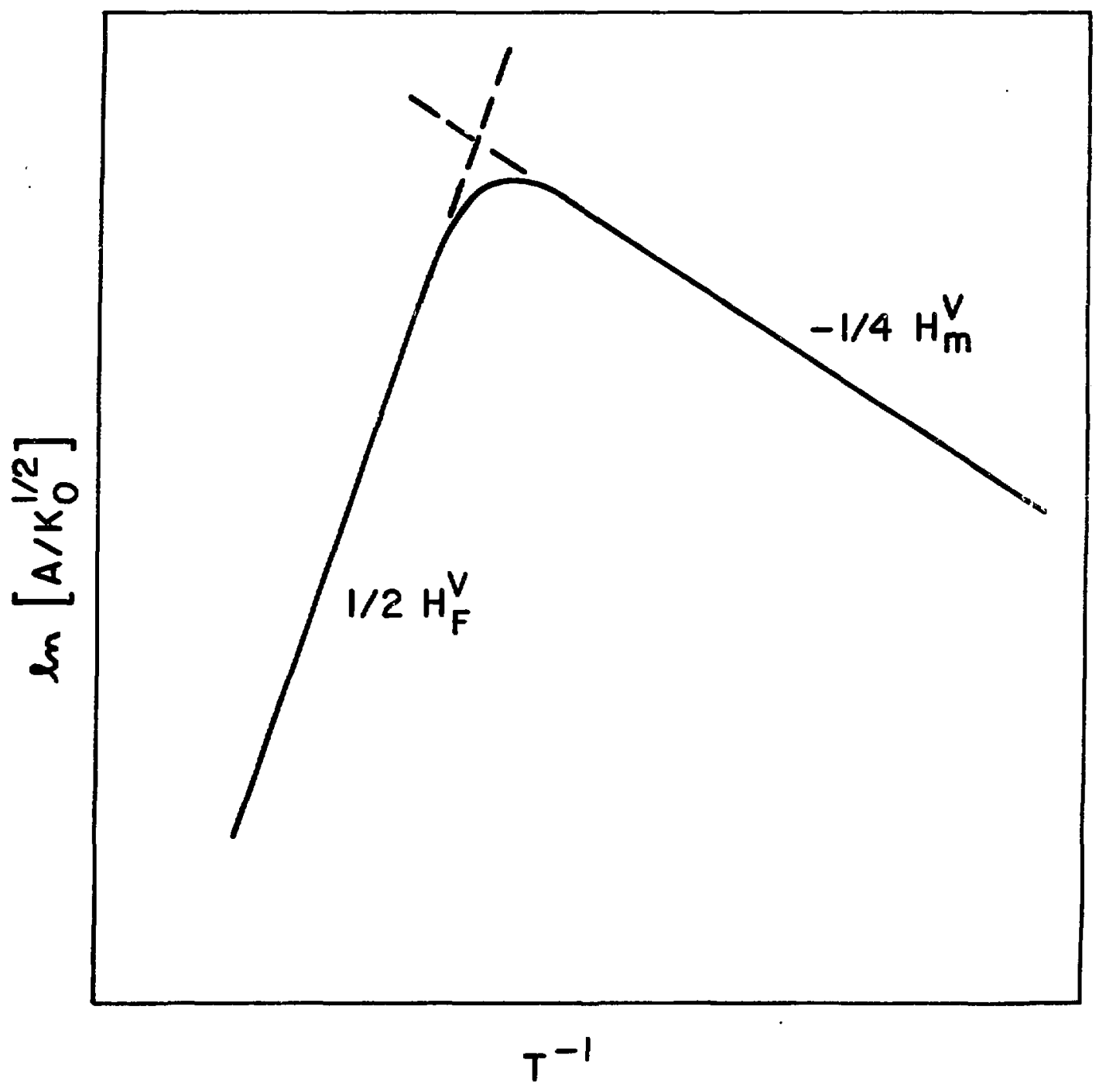

- FIg. 1 


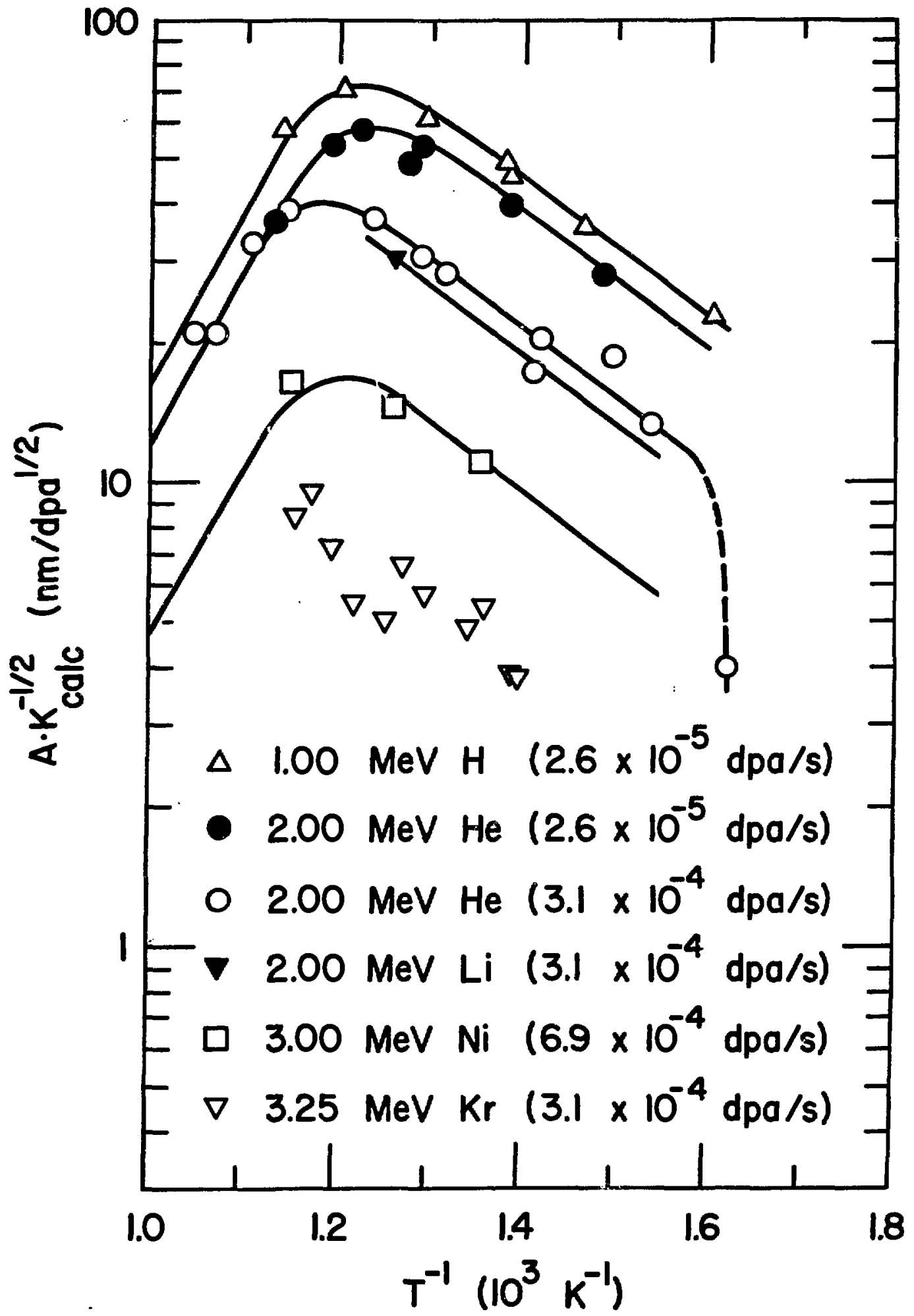

F1g. 2 


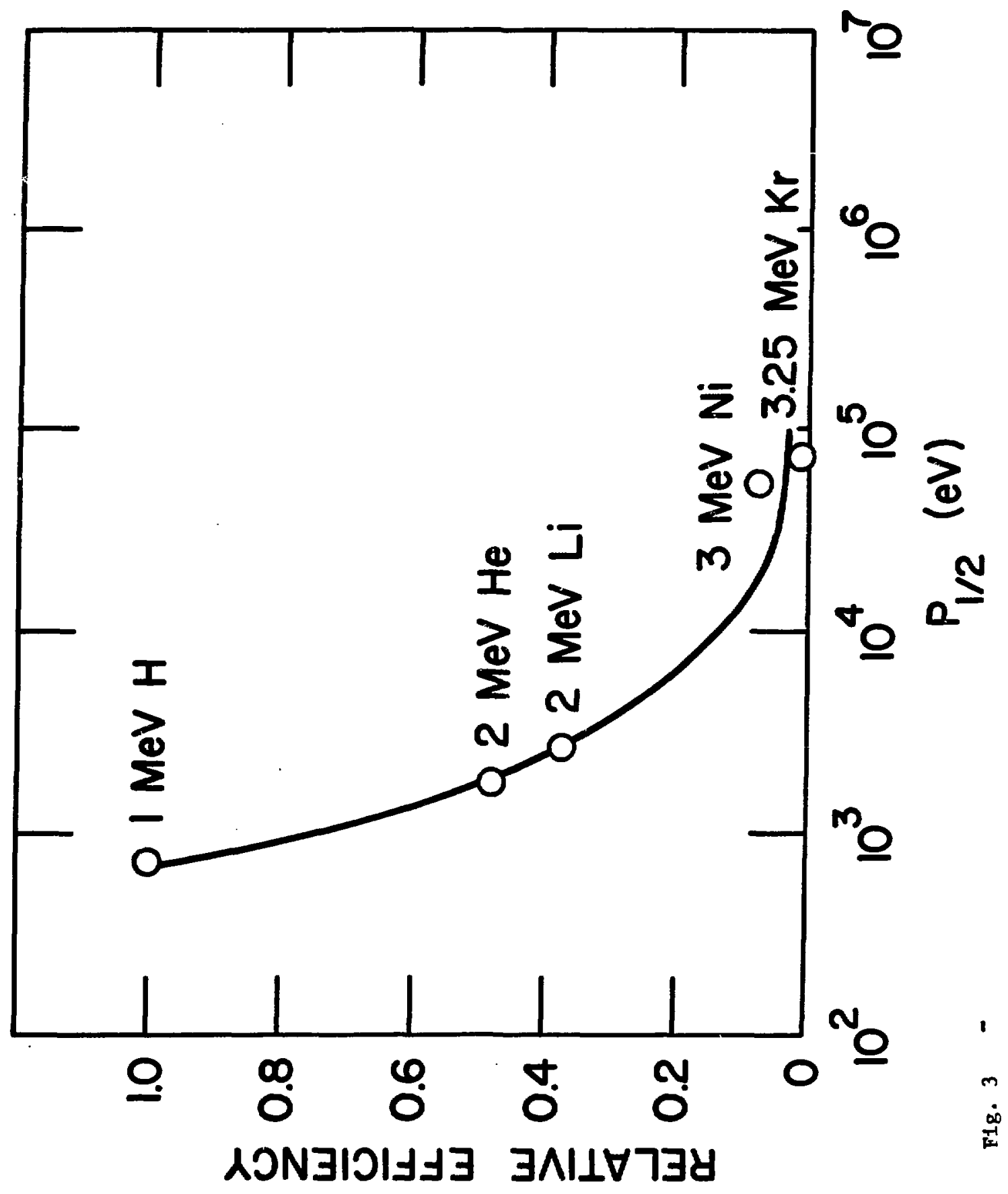

